\title{
Breaking the Rules: Low Trait or State Self-Control Increases Social Norm Violations
}

\author{
Matthew T. Gailliot ${ }^{1}$, Seth A. Gitter ${ }^{2}$, Michael D. Baker ${ }^{3}$, Roy F. Baumeister ${ }^{4}$ \\ ${ }^{1}$ Psychology Department, Stephen F. Austin State University, Nacogdoches, USA \\ ${ }^{2}$ US Army Research Institute for the Behavioral Sciences, Ft. Benning, USA \\ ${ }^{3}$ Psychology Department, East Carolina University, Greenville, USA \\ ${ }^{4}$ Psychology Department, Florida State University, Tallahassee, USA \\ Email: mgailliot@gmail.com, seth.a.gitter.civ@mail.mil, bakermich@ecu.edu, baumeister@psy.fsu.edu
}

Received August 15 $5^{\text {th }}, 2012$; revised September 12 $2^{\text {th }}, 2012$; accepted October $11^{\text {th }}, 2012$

\begin{abstract}
Two pilot and six studies indicated that poor self-control causes people to violate social norms and rules that are effortful to follow. Lower trait self-control was associated with a greater willingness to take ethical risks and use curse words. Participants who completed an initial self-control task that reduced the capacity for self-control used more curse words and were more willing to take ethical risks than participants who completed a neutral task. Poor self-control was also associated with violating explicit rules given by the experimenter. Depleting self-control resources in a self-control exercise caused participants subsequently to talk when they had been instructed to remain silent. Low trait self-control and poor performance on a behavioral measure of self-control (the Stroop task) predicted poor compliance following experimental instructions over a 2-week span. Poor self-control thus undermines adherence to some social rules and regulations, therefore possibly contributing to a broad variety of social ills.
\end{abstract}

Keywords: Ego Depletion; Social Norms; Self-Control; Self-Regulation; Ethical Behavior; Risk Taking; Reciprocity

\section{Introduction}

The capacity to follow rules and regulations is far more advanced among humans than among any other species (e.g., Baumeister, 2005). Without this vital capacity, modern society would cease to function in any meaningful form. Adherence to social regulations (e.g., norms, morals, and laws) seems especially important, bestowing numerous benefits on members of society collectively and individually. When society's members comply with its regulations, they can expect to experience healthier, safer, and generally more desirable lives as a result.

People oftentimes violate norms and regulations, however, sometimes with devastating consequences (e.g., death, rape, addiction, prison). Understanding why people violate social regulations thus offers great promise for alleviating numerous social ills and increasing life satisfaction. The current work therefore examined one potentially important reason that people fail to follow social regulations.

Following social regulations is sometimes effortful and demanding, and in these situations should therefore require self-regulation or self-control (i.e., the process of controlling ones' thoughts, emotions, or urges, or altering one's habitual behaviors). What the individual wants to do (e.g., seek immediate gratification) sometimes conflicts with what social regulations would recommend (e.g., wait your turn), and so the individual must exert self-control so as to bring his or her behavior into line with societal standards. The main hypothesis of the current work was therefore that poor or impaired self-control would make people less likely to abide by social norms and regulations that involve a conflict between what the individual wants to do and what the individual ought to do.

\section{Self-Regulation: Trait and State Differences}

The current work examined both dispositional and temporary impairments to self-control. People differ in their dispositional capacity to self-regulate, such that some people are clearly more capable of self-regulating than others. The ability to self-regulate appears to be stable across the lifespan, with individual differences during childhood enduring into adulthood (e.g., Mischel, Shoda, \& Peake, 1988). Such differences in self-control are related to a broad range of desirable outcomes. People with high (as compared to low) trait self-control show greater interpersonal popularity and healthier relationships, superior school performance, and better coping skills and mental heath (e.g., Finkel \& Campbell, 2001; Mischel et al., 1988; Tangney, Baumeister, \& Boone, 2004). Trait self-control thus appears to be highly adaptive and beneficial across numerous life domains.

Though self-regulation capacity differs as a trait, it also differs as a state, such that any one individual is more capable of self-regulating at some times than at others. In particular, the use of self-control appears to resemble a muscle or limited stock of energy that becomes depleted with use (for reviews, see Baumeister, Schmeichel, \& Vohs, 2005; Muraven \& Baumeister, 2000). Performing one task that requires self-control consumes self-regulatory strength, such that performance on other, subsequent self-regulatory tasks is impaired. In one study, for instance, participants who had to resist eating freshly baked cookies subsequently quit sooner on a task requiring effortful persistence, compared to participants who did not have to resist eating cookies, consistent with the idea that their self-regulatory resources had been depleted by resisting the temptation to eat cookies (Baumeister, Bratslavsky, Muraven, \& Tice, 1998). 
Indeed, multiple findings demonstrate that people become less capable of self-regulating after their self-regulatory resources have been depleted (e.g., Finkel \& Campbell, 2001; Richeson \& Shelton, 2003; Schmeichel, Vohs, \& Baumeister, 2003). When their self-control strength has been depleted, people are less capable of refraining from eating (Kahan, Polivy, \& Herman, 2003), limiting their alcohol intake (Muraven, Collins, $\&$ Neinhaus, 2002), and suppressing unwanted thoughts (Gailliot, Schmeichel, \& Baumeister, 2006).

The capacity for self-control thus differs as a trait and also as a state, and such differences have been shown to predict self-regulatory performance in numerous domains. The current work examined whether low trait self-control and state selfcontrol depletion would cause failures in following some social regulations.

\section{Social Norms and Rules and Self-Regulation}

Self-control is powerfully adaptive and might be especially useful for enabling people to follow social regulations. From an evolutionary perspective, self-regulation possibly paved the way for participation in culture, by allowing people to control their selfish and uncivilized urges for the sake of getting along with others. As a result, people were better able to cooperate with one another and work toward long-term goals, thereby facilitating survival and reproduction. Self-regulation may possibly have evolved in part to allow people to conform to social norms and regulations.

Some findings are consistent with the view that self-control might enable people to follow social norms and rules. For instance, low self-control is one of the leading causes of criminal behavior (Gottfredson \& Hirschi, 1990; Pratt \& Cullen, 2000), and criminal behavior is by definition a direct violation of society's official rules. Further, low self-control seems to undermine sexual restraint, thereby contributing to socially inappropriate sexual acts (Gailliot \& Baumeister, 2005). Thus, when people lack self-control, they seem prone to violate norms of sexuality and lawful behavior.

\section{Research Overview}

The current work tested directly whether low self-control would cause people to violate social norms and other rules involving a conflict between personal desires and external demands. To provide converging evidence, we both assessed and manipulated self-control. To reduce the possibility that our results could be attributable to artifact of some particular procedure, we used a variety of methods, including self-report and behavioral measures.

To increase the generalizability of the findings, we also used a variety of methods to assess adherence to social regulations. The first set of studies examined the role of self-control in following more subtle or implicit norms. Specifically, we first examined ethical behavior (Study 1), the use of profanity (Study 2), and social reciprocation (Study 3). We predicted that impaired self-control (low trait self-control or depletion) would increase the likelihood that participants would violate social regulations, such that they would be more likely to behave unethically, use profanity, and violate norms of reciprocity.

The purpose of the second set of studies was to demonstrate that low self-control causes people to violate social rules even when these rules are highly salient, explicit, and clearly di- rected toward the individual. Specifically, participants were instructed to refrain from talking while being alone with their current dating partner (Study 5), to change how they normally spoke (Study 5), or to use their non-dominant hand for a variety of tasks (Study 6). Low self-control should undermine the ability to adhere to explicit social regulations, and so those with low (versus high) self-control should be more likely to fail to follow instructions to refrain from talking, speak differently, or use their non-dominant hand.

\section{Study 1}

Study 1 examined whether low self-control would increase the likelihood that people would violate ethical rules of conduct by engaging in ethical risks. Ethical behavior is by definition what society has deemed as being good and desirable, and so behaving unethically can be considered a direct violation of social regulations. In order to behave ethically, people must override their selfish or antisocial desires and instead abide by rules of appropriate conduct. It seems plausible that self-control enables individuals to override such desires and behave ethically (Baumeister \& Exline, 1999; Gailliot \& Baumeister, 2005). If people are less able to self-regulate, then they should be more likely to give in to their socially inappropriate desires and engage in unethical behavior.

Two pilot studies demonstrated a link between low self-control and unethical behavior. In one study, participants completed the trait Self-Control Scale (Tangney et al., 2004) and the abbreviated Risk Taking Behaviors Scale (RTBS; Weber, Blais, \& Betz, 2002), which contains 5 items that assess one's willingness to take ethical risks (e.g., forging a signature, cheating on an exam, taking credit for someone else's work). Low trait self-control predicted a greater willingness to take ethical risks, $r(42)=-.31, p<.05$. In the other pilot study, participants completed the State Depletion Scale (Twenge, Muraven, \& Tice, 2004; for a similar measure, see Finkel \& Campbell, 2001), which assesses perceptions of currently available self-regulatory resources, and the full version of the RTBS. Stronger perceptions of depletion predicted a greater willingness to take ethical risks, $r(148)=.21, p<.05$. In sum, two pilot studies suggested that low trait or depleted self-control might predispose one to engage in unethical behavior.

The correlational nature of the pilot data clearly precludes drawing any firm causal conclusions, however. The purpose of Study 1 was therefore to develop a stronger causal conclusion by manipulating self-regulatory strength and then measuring subsequent willingness to take ethical risks.

The manipulation of self-regulatory strength was derived from past research (e.g., Baumeister et al., 1998). For this manipulation, participants first crossed out letters on a page of text according to a specific set of instructions so as to establish a habit or routine of crossing out letters. For participants in the self-control depletion condition, they were then required to override this habit by crossing out letters according to a revised, more complex rule that in some (but not all) cases contradicted the rule they had learned. Self-control is required to override a previously established habit, and so following the new routine is posited to deplete self-regulatory strength. In the no-depletion condition, participants followed the same rule that they learned initially and thus had to exert little or no self-control because they were not required to override any habit.

At the end of this task, participants completed the RTBS as a 
measure of ethical risk taking. If low self-control undermines the likelihood of following social norms, then participants who had to exert and therefore depleted their self-control during the crossing out letters task should be more likely to take ethical risks than those who did not have to exert self-control.

\section{Method}

Participants. Participants in this and all subsequent studies were undergraduate students enrolled in introductory psychology courses who received credit toward fulfilling a course requirement. Fifty-five students (34 women) participated in Study 1. They were randomly assigned to a self-control depletion or no-depletion condition.

Procedure. Participants were run individually or in pairs and were told that the study wasinvestigating personality. They received a questionnaire packet that contained all materials for the study and worked through the packet at their own pace.

First, participants completed a task that required the crossing out of letters on a page of text, which served as the depletion manipulation. Specifically, participants were given two copies of a page of typewritten text taken from a scientific journal article. On the first page, participants were instructed to cross out every occurrence of the letter $e$. The page contained a high number (337) of es and so participants should have established a well-practiced routine of crossing out es. For the second page of text, participants assigned to the no-depletion condition were asked to follow the same rule as before by crossing out all occurrences of the letter $e$. This task required a high number of responses and so was somewhat demanding for these participants. Participants in the depletion condition, however, were asked to follow a different rule than before by crossing out all occurrences of the letter $e$ except for $e$ s that were followed by a vowel or es that appeared in a word with a vowel appearing two letters before the $e$. Thus, this task demanded fewer responses but more overriding of incipient responses.

Next, participants completed the Brief Mood Introspection Scale (BMIS; Mayer \& Gaschke, 1988) as a measure of mood valence and arousal. The BMIS contains 20 items indicative of mood (e.g., happy, sad) and arousal (e.g., peppy, drowsy). Participants were asked to rate each item on the extent to which that item described how they were feeling at the present moment on a scale from 1 (definitely do not feel) to 7 (definitely feel).

The following pages in the packet contained the final dependent measure of ethical risk taking, the full version of the RTBS (Weber et al., 2002), and two filler questionnaires (the order of which was counterbalanced across participants). The full version of the RTBS contains 8 items pertaining to ethical risks and 32 items pertaining to non-ethical risks. Afterward, participants completed a single item measure of self-efficacy ("How well do you feel like you did on the crossing out es task?") and demographic information. Last, participants were thanked and debriefed.

\section{Results and Discussion}

Depletion and Risk-Taking Behavior. We predicted and confirmed that self-control depletion would cause participants to break social norms such that depletion would increase ethical risk taking. Depleted participants indicated that they were more likely to take ethical risks $(M=1.70, S D=.55)$ than did nonde- pleted participants $(M=1.42, S D=.34), t(43)=2.03, p<.05$. The difference between the two conditions was medium in size, $d=.64$. Thus, when participants' self-regulatory strength had been depleted by a prior self-regulatory task, they indicated being more likely to violate social norms by taking ethical risks, such as forging a signature or taking credit for another's work.

We also examined whether depletion influenced willingness to engage in risks more generally, as assessed by the 32-item measure of non-ethical risks on the RTBS. Depleted and non-depleted participants did not differ in the perceived likelihood of engaging in non-ethical risks, $t<1$, ns. This provides some evidence that the effect of low self-control upon risk taking may have been specific to ethical risk taking rather than to risk taking in general.

Mood, Arousal, and Self-Efficacy. We also assessed whether the difference in ethical risk taking between depleted and nondepleted participants was attributable to or mediated by mood valence or arousal (as assessed by the BMIS immediately after the $e$ s task) or how well participants thought they did on the es task (assessed at the end of the experiment). Tests of mediation require that a mediator be significantly related to both the independent and dependent variables (Baron \& Kenny, 1986). Analyses indicated that these criteria were not met for mood, arousal, or self-efficacy. For instance, none of these factors was significantly related to ethical risk taking, all $r \mathrm{~s}<.19$. These results suggest that the relationship between depletion and ethical risk taking was probably not attributable to mood, arousal, or self-efficacy.

\section{Study 2}

Norms surrounding ethical risk taking might be closely tied with self-control because unethical behavior is strongly discouraged, such that people are highly attuned toward detecting cheaters and unethical behavior (e.g., Cosmides \& Tooby, 2004). Study 2 therefore sought to build upon the results of Study 1 by examining whether low trait self-control and depletion would be related to violations of a norm not directly related to ethical behavior - avoiding the use of curse words. Social norms typically discourage the use of curse words, especially in public settings (e.g., Rubens, 1981), and so we considered the use of curse words as an appropriate measure of following social norms.

Specifically, as in Study 1, we assessed self-control using the trait measure and manipulated self-control strength using the es task. To assess the likelihood of violating social norms, we used a behavioral measure in which participants completed word puzzles that could be solved with either curse or noncurse (neutral) words. We predicted that low self-control would increase the tendency to violate social norms. Therefore, participants with low or depleted self-control should respond with more curse words than participants with higher self-control.

\section{Method}

Participants. Participants were 86 undergraduates (65 women). Participants were randomly assigned to a self-control depletion or no-depletion condition.

Procedure. Assessment of trait self-control: Participants completed the brief 13-item measure of trait self-control (Tangney et al., 2004) during a mass testing session at the start 
of the semester. One item from the self-control scale (i.e., "I say inappropriate things") was in principle related to the dependent measure. To avoid being tautological, we therefore excluded responses to this item from the final measure of trait self-control (though the results remained relatively unchanged when including responses to this item). Eighteen participants did not complete the mass testing session. They were therefore excluded from all analyses involving trait self-control.

Experimental session: Participants completed the main phase of the experiment approximately 3 months after the mass testing session. They were run in a classroom setting and were told that the study was investigating attitudes and opinions. They received a questionnaire packet that contained all materials for the study and worked through the packet at their own pace.

First, participants completed the same crossing out es task used in Study 1b. At the end of the task, participants completed a rough check of the self-regulatory demand of the task by indicating how difficult the task was on a scale from 1 (not at all difficult) to 7 (very difficult). Next, participants completed some filler questionnaires and demographic information.

Last, participants completed a list of 31 word fragments and 4 anagrams, all of which had multiple, non-curse word solutions (e.g., BUCK, DUCK, MUCK, TUCK, WITCH, DITCH, HITCH, HITS). For the target items, two word fragments (i.e., U C K, _ I T C H) and one anagram (HSIT) could also be solved with a curse word. The number of target items solved with curse words constituted the dependent measure of violating social norms. Responding with more (rather than fewer) curse words indicated violating social norms to a greater extent.

\section{Results and Discussion}

Self-Control Depletion and Curse Words. We predicted and confirmed that depletion would increase the number of target word puzzles solved with curse words. Gender was included as a factor in the analysis because of the common assumption that men curse more than women. A 2 (depletion condition) X 2 (gender) analysis of variance (ANOVA) indicated that depleted participants responded with more curse words $(M=1.07, S D$ $=.88)$ than did non-depleted participants $(M=.66, S D=.71), F$ $(1,82)=4.70, p<.05, d=.51$. This suggests that depletion increased the likelihood of violating social norms, such that temporarily depleted self-control was associated with responding with more curse words.

Further, men responded with more curse words $(M=1.19$, $S D=.93)$ than did women $(M=.75, S D=.79), F(1,82)=5.36$, $p<.05, d=.54$. The interaction between depletion condition and gender did not approach significance, $F<1$, ns. Thus, depletion increased the propensity to respond with curse words equally among male and female participants.

Trait Self-Control and Curse Words. Another prediction was that participants low in trait self-control would respond with more curse words than those high in trait self-control. This prediction was confirmed. Trait self-control was negatively and significantly related to the number of target items solved with curse words, $r(68)=-.29, p<.05^{1}$. Thus, dispositionally poor self-control, like self-control depletion, also contributed to violating social norms. Both experimental manipulations of selfcontrol and dispositional differences in self-control thus converged on the conclusion that less self-control leads to more violations of social norms.

\section{Study 3}

Study 3 examined the effect of self-control depletion on following norms of reciprocity. Norms of reciprocity are among the most widely documented and strongest of social norms, even across many different cultures (e.g., Fisher, DePaulo, \& Nadler, 1981; Gouldner, 1960; Greenberg, 1980). When someone performs a favor for another, the reciprocity norm entails some obligation on the recipient to return the favor. Reciprocity may also entail that someone should not do a favor for a person who has refused to do a favor for that person.

In Study 3, participants completed the same crossing out es task used in the previous studies and thus either did or did not have to exert self-control. After this task, participants in the favor condition received a favor (being allowed to leave early from the experiment) from the experimenter, whereas those in the no-favor condition did not. Last, participants were given the opportunity to reciprocate by doing or not doing a favor for the experimenter by volunteering at a local homeless shelter.

Research on the norm of reciprocity suggests that participants should be more likely to do a favor for the experimenter when the experimenter does a favor for them, and less likely to do a favor when the experimenter does not do a favor for them. If low self-control causes people to fail at following social norms, then low self-control should reduce compliance with norms of reciprocity.

\section{Method}

Participants. Participants were 86 undergraduates (47 women). Two participants indicated suspicion about the final dependent measure (see below) and therefore were excluded from all analyses, leaving a final sample of 84 (45 women). Participants were randomly assigned to condition.

Procedure. Participants were run individually and were told the study was investigating the relationship between editing papers and social interactions. As part of a cover story, participants were also told that they would be working with another participant during the latter part of the experiment.

First, participants completed the same crossing out es task used in the previous studies. To bolster the cover story, the experimenter stated prior to the start of this task that the other participant had not yet arrived but that the participant could begin.

The next part of the study constituted the manipulation of social norms (modified from Regan, 1971). Specifically, participants were told that they were supposed to have an interaction with the other participant but that this person had not shown up. To establish a norm of giving favors, those in the favor condition were told that the experimenter would allow them to leave early and would give them full credit despite their not having completed the latter half of the experiment. To establish a norm of not giving favors, those in the no-favor condition were not told that they would be given credit for the experiment at that point. Instead, they were told that they had to work on another task for the next 30 minutes in order to receive full credit. (For ethical purposes, however, the consent form stated that participants were allowed to leave at any point during the experiment and would still receive the appropriate

\footnotetext{
${ }^{1} \mathrm{~A}$ regression analysis indicated that this effect was not moderated by depletioncondition. This finding is consistent with other research (Gailliot \& Baumeister, 2005) showing that self-control depletion and trait self-control each contribute to self-regulation but that the two do not interact.
} 
amount of credit.)

Immediately after the manipulation of favor norms, participants were given the opportunity to do a favor for the experimenter. Specifically, the experimenter stated that he or she worked at a local homeless shelter and was hoping that the participant would do a favor for him or her by volunteering at the shelter. Participants then completed a bogus volunteer sheet on which they indicated whether they would be willing to volunteer and for how many hours. The number of hours constituted the dependent measure of following social norms. In the favor condition, volunteering for more hours indicated following the norm of giving. In the no-favor condition, however, volunteering for fewer hours indicated following the norm of not giving. Hence, in the no-favor condition, we reverse scored the number of hours for which participants volunteered.

\section{Results and Discussion}

We predicted that depletion would reduce the likelihood that participants would follow social norms of reciprocation. A 2 (Depletion condition: Depletion vs. no-depletion) $\times 2$ (Favor condition: Favor vs. no-favor) analysis of variance (ANOVA) confirmed this prediction. The analysis indicated a significant main effect of depletion condition, $F(1,80)=4.25, p<.05, d$ $=.46$. Participants in the depletion condition $(M=1.55, S D=$ 2.18 ) reciprocated to a lesser extent than did participants in the no-depletion condition $(M=2.60, S D=2.39)$. This result underscores the notion that low self-control causes violations of social norms. Depleted participants failed to follow norms of reciprocity.

The main effect of favor condition and its interaction with depletion condition were not significant, both $F_{\mathrm{s}}<.02$, ns. Thus, depletion reduced reciprocity regardless of whether the norm was to perform or not perform a favor.

\section{Study $4^{2}$}

Studies 1-3 demonstrated that following social norms requires self-control, such that low self-control caused people to violate established social norms (ethics, profanity, reciprocity). Rather than examine established, implicit social norms, Studies 4-6 sought to build upon the previous studies by devising new regulations and making it explicitly clear to participants that they were supposed to follow these rules. If low self-control causes violations of social regulations, then people with low (state or trait) self-control should be relatively more likely to disobey explicit instructions from the situational authority figure, in this case the experimenter.

In Study 4, participants were asked to refrain from talking during part of the experiment, and we examined whether self-control depletion would cause participants to break this rule. Specifically, participants first watched a video of a woman talking as words (unrelated to the woman's talking) appeared below. Participants in the self-control depletion condition were asked to focus only on the woman and to ignore the words on the screen. Attention automatically orients toward novel stimuli appearing in the environment (e.g., Shiffrin \& Schneider, 1977), and so the task required these participants to exert self-control by overriding pre-potent orienting of attention to the words and maintain attention instead only on the woman. We expected that this initial act of self-regulation would deplete participants' self-regulatory strength, as in prior research (e.g., Schmeichel et al., 2003). Participants in the no-depletion condition were asked to watch the video as they would normally and hence were not required to control their attention or exert active self-control.

Participants then completed a task with their current dating partner. For this task, each partner was explicitly instructed to avoid talking with his or her partner. If low self-control causes people to violate social rules and regulations, even those recently formed, then depleted participants should be more likely to talk than non-depleted participants.

\section{Method}

Participants. Undergraduates currently dating someone with whom they would be comfortable engaging in some sort of physical intimacy (e.g., holding hands) were invited to participate. Participants were 21 male-female romantic couples that chose to sign up for the study in connection with course requirements for one or both members of the couple. Each couple was randomly assigned to a self-control depletion or no-depletion condition.

Procedure. Participants arrived at the study with their current romantic partner and were seated in separate rooms. Participants were told the study was examining the relationship between task performance and intimacy in relationships. The first task served as the manipulation of self-regulatory resources. Specifically, participants watched a 6 minute video (without sound) of a woman talking. In the bottom corner of the screen, words (e.g., hair, hat, pulse) appeared individually for $10 \mathrm{sec}-$ onds (modified from Gilbert, Krull, \& Pelham, 1988). Participants in the depletion condition were instructed to focus their attention only on the woman's face and to refrain from looking at the words. If they happened to look at the words, they were to re-focus their attention on the woman as quickly as possible. Participants in theno-depletion cond-itionwere instructed to watch the video as they would normally (i.e., as if they were sitting at home watching television). Upon finishing their respective tasks, participants completed amanipulation check and the BMIS to assess mood and arousal (Mayer \& Gaschke, 1988).

Next, participants were instructed that they would complete a task to assess how people express physical intimacy in their relationships. Participants were asked to express some sort of physical intimacy (e.g., holding hands, hugging) with their dating partner and that it was entirely up to them as to what they did (provided that both partners consented to the behavior). Participants were told that they would have complete privacy and were given 3 minutes to complete this task.

Most importantly for current concerns, participants were explicitly instructed to not talk during this task. At the end of the task, participants were taken to separate rooms and were given a questionnaire on which they were to indicate whether (yes or no) they had talked during the task, and thus violated experimental instructions. To increase the likelihood that participants would respond honestly, they were reminded to answer truthfully and that it was okay if they did talk-we simply wanted to

\footnotetext{
${ }^{2}$ Studies 4-6 were conducted to test other hypotheses irrelevant to the present investigation, and those results (using measures other than what is reported here) have in some cases been written up in other works. Hence the data reported here represent secondary reanalyses of existing data. The specific findings reported here have not been reported elsewhere, however. We included them here because they presented a very helpful opportunity to investigate whether low self-control would affect whether participants followed an assortment of explicit, specific instructions.
} 
know the truth. Couples for whom at least one dating partner indicated having talked were considered as having talked and thereby having breached the experimental rule. Last, participants were thanked and debriefed.

\section{Results and Discussion}

We predicted and confirmed that depletion would increase the likelihood that participants would violate the experimental rule to refrain from talking. Depleted couples were more likely to indicate having talked than were non-depleted couples, $\chi 2(1$, $N=21)=3.83, p=.05$. Whereas $70 \%$ of depleted couples indicated that they had talked, only $27 \%$ of non-depleted couples indicated that they had talked ${ }^{3}$. Thus, self-control depletion caused participants to violate a social rule — not talking — given to them by the experimenter.

\section{Study 5}

If low self-control causes people to fail at following novel social rules, then trait self-control (in addition to depletion) should be related to the extent to which people abide by others' rules. Study 5 therefore assessed trait self-control and examined whether participants with low trait self-control would adhere less faithfully to experimental instructions than those with high trait self-control.

For the experimental instructions, participants were asked to alter their customary mode of speaking for 2 weeks. We predicted that participants low in trait self-control would more poorly follow these instructions, compared to those high in trait self-control.

\section{Method}

Participants. Participants were 48 undergraduates (32 women). Three participants did not return for the second experimental session. Their data therefore were excluded from all analyses, leaving a final sample of 45 (29 women).

Procedure. Participants were run individually and told that the study was examining how different aspects of people's personality (e.g., attitudes and verbal abilities) are related. During an initial experimental session, they completed tasks (e.g., solving anagrams) in the exploration of other issues.

At the end of the session, participants were given journals that stated that they were to modify their manner of speaking for the next 2 weeks (borrowed from Oaten, Cheng, \& Baumeister, 2004). Specifically, they were asked to only say "yes" and "no" instead of using similar colloquialisms (e.g., yeah, yup, nope, nah), to speak only in full and complete sentences, to avoid using sentences that began with "I", and to not use slang or swear words. Participants were also asked to record in the journals how well they had followed the instructions. At the end of each day, participants were to record how often they complied with each of the different requirements, using a scale from 1 (never) to 9 (all the time). These responses were averaged to create the final dependent measure of how well partici-

\footnotetext{
${ }^{3}$ For three couples, one partner indicated that the couple had talked, whereas the other partner indicated that they had not. Excluding these couples from the analyses produced the same result. More couples in the depletion condition $(66.7 \%)$ indicated having talked than did those in the no-depletion condition $(11.1 \%), \chi^{2}(1, N=18)=5.84, p<.05$. Similarly, considering each of these three couples as having either talked or not talked produced the same result, both $p s<.05$.
}

pants followed the instructions.

The journals stressed the importance of remembering to follow the instructions each day. However, they also made it explicitly clear that it was essential for participants to be honest in reporting how well they followed the instructions and that their receiving credit for the study was in no way contingent upon their responses.

At the end of the 2 weeks, participants returned for a second experimental session and returned their completed journals. After completing some activities similar to those in the first session, participants completed the full version of the Trait Self-Control Scale (Tangney et al., 2004). The Self-Control Scale contains 36 items (e.g., "I have a hard time breaking bad habits", "I am good at resisting temptation") answered on a scale from 1 (not at all like me) to 5 (very much like me). Participants were last thanked and debriefed.

\section{Results and Discussion}

Trait self-control correlated positively and moderately strong with following the instructions, $r(45)=.53, p<.001$. Participants high in trait self-control reported having followed the speech modification exercises more faithfully than those low in self-control. Self-control thus seems to enable people to follow artificial rules, such as those given by an experimenter, as well as pre-existing social norms.

One might wonder whether the results are circular or trivial in the sense that items on the trait self-control scale may have been directly related to participants' willingness to follow the experimental instructions. Inspection of the scale revealed no such items. The self-control scale is based on behavioral measures (e.g., "I spend too much money", "I lose my temper too easily") that are not directly related to the experimental instructions used in the current study. It therefore seems likely that low self-control lends itself to a personal disposition toward breaking social rules and other regulations, rather than simply a disregard for only experimental instructions.

\section{Study 6}

Study 6 constituted a conceptual replication of Study 5 that used a different operationalization of trait self-control and a different instructional task (i.e., using one's nondominant hand). We also added a no-exercise control condition to determine whether self-control was related to the exercises we used even when participants were not instructed to complete the exercises.

Specifically, as a measure of trait self-control, participants completed the Stroop color word interference task. The Stroop task is one of the most frequently used measures of self-control (see MacLeod, 1991). For this task, participants had to indicate the color ink of color words (e.g., red). On some trials, the color ink and meaning of the word were different (e.g., red appeared in blue ink), and these trials required self-control because participants had to inhibit the tendency to read the words and instead respond according to the color ink. Responding faster on these trials and with fewer errors indicated superior performance and hence higher self-control. This approach thus complements our use of standard self-report trait scales in the other studies by providing a behavioral measure. In essence, this study assessed self-control by seeing how people would actually control their behavior, as opposed to asking them to report on their general tendencies to control their behavior. 
After completing this task, participants received one of two sets of instructions. Those in the exercise instructions condition were asked to use their non-dominant hand for a variety of tasks for the next 2 weeks, whereas those in the no-exercise instructions condition were asked to record the frequency with which they used their non-dominant hand for the same tasks. If self-control enables people to more effectively follow rules and regulations, then participants who perform better on the Stroop task (indicative of higher trait self-control) should follow the exercise instructions more faithfully than those who perform worse.

\section{Method}

Participants. Participants were 81 undergraduates (66 women) who participated in exchange for course credit and $\$ 10.00$. Two participants did not understand the Stroop task instructions. Their data therefore were excluded from all analyses, leaving a final sample of 79 (64 women). Participants were randomly assigned to an exercise or no-exercise instructions condition.

Procedure. Participants were run individually and were told that the study was examining how different aspects of people's personality (e.g., attitudes and verbal abilities) are related. During an initial laboratory session, participants completed the Stroop task on the computer and some filler measures unrelated to the current investigation.

For the Stroop task, participants completed 3 blocks of trials. The first block consisted of practice trials to familiarize participants with how to respond on the keyboard. Specifically, participants completed 30 trials in which a string of Xs ("XXXXX") appeared on the computer screen in either red, blue, or green colored font. Participants were to indicate the color of the Xs by pressing one of three computer keys (the R, $\mathrm{G}$, or B key) as quickly as possible. Following each response, the next string of Xs appeared immediately.

For the next two blocks, participants completed trials in which the word red, blue, or green appeared on the computer screen in either red, blue, or green colored font. Participants were to indicate the font color by pressing one of three computer keys and were asked to respond as quickly and accurately as possible. The first block consisted of 30 congruent trials in which the meaning and font color of the word were the same. The second block consisted of 30 incongruent trials in which the meaning and font color of the word were different.

At the end of the session, participants were given journals similar to those used in Study 5. For participants in the exercise instructions condition, the journals instructed them to use their non-dominant hand (e.g., their left-hand if they were righthanded) for a variety of tasks (i.e., brushing their teeth, opening doors, eating with utensils, using tools, carrying and holding items, using a computer mouse, and stirring drinks). Participants in the no-exercise instructions condition were asked only to complete the journals. At the end of each day, participants were to record how often they had used their non-dominant hand for each of the different behaviors, using a scale from 1 (never) to 9 (every chance I had). These responses were averaged to create the final dependent measure of how often participants used their non-dominant hand. For those in the exercise instructions condition, this measure therefore indicated the extent to which they had followed the handedness exercise instructions.
To increase participants' motivation to complete the journals and follow the instructions, the experimenter stressed to each participant the importance of following the instructions. This message was also reiterated in the journals. Further, participants were reminded that they would receive $\$ 10.00$ as an additional incentive to follow the instructions. Thus, participants should have been highly motivated to follow the instructions. However, we also made it explicitly clear that it was important for them to be honest and accurate in reporting how well they followed the instructions and that their receiving credit and payment for the study was in no way contingent upon their responses in the journals. Participants returned their completed journals at the end of the two weeks.

\section{Results and Discussion}

For the Stroop task, participants were asked to respond as quickly and accurately as possible. We therefore standardized average reaction times (reverse scored) and percent of correct responses for congruent and incongruent trials, respectively, and then we combined these two measures to create two dependent measures of Stroop task performance-one for congruent trials and one for incongruent trials.

To the extent that Stroop performance (on incongruent trials) is indicative of trait self-control, participants who performed better on the Stroop task should have more faithfully followed the exercise instructions. This prediction was confirmed. In the exercise instructions condition, performance on incongruent trials was positively and significantly related to the extent to which participants used their non-dominant hand, $r(31)=.40, p$ $<.05$ (for accuracy, $r=.36, p<.05$; for speed, $r=.33, p=.07$ ). Those who performed better on incongruent trials did a better job of following the handedness instructions.

This relationship was not significant in the no-exercise instructions condition, $r<.12$, ns. Thus, when participants were not instructed to use their non-dominant hand, the frequency with which they used their non-dominant hand was not related to performance on incongruent trials. Likewise, performance on congruent trials was not related to the frequency with which participants used their non-dominant hand in either exercise instruction condition, both $r s<.20$, ns. Thus, only performance on trials that required self-control (incongruent trials) was significantly related to following the handedness instructions.

These results thus provide converging evidence that low self-control reduces the likelihood of following social norms and other rules. Participants low in self-control, as defined by performance on incongruent trials on the Stroop task, followed their exercise instructions less faithfully than participants high in self-control, over the two weeks. Once again, those low in self-control apparently lacked the capacity or willingness to adhere to the experimental instructions.

\section{General Discussion}

Self-regulation can be regarded as a vital social trait. Although it probably offers some benefits even to creatures who live solitary lives and interact mainly with their physical environments, it is much more widely useful to social beings, because it enables them to override their responses and impulses, especially antisocial ones. Human social life requires people to subdue a broad variety of selfish and otherwise disruptive impulses so as to avoid conflict, live together harmoniously, and 
sustain the high level of interactive activity that makes up human culture. In particular, people must alter their behavior to conform to a great many rules, ranging from laws and morals to implicit and informal norms.

In a nutshell, human social life is full of rules and depends on them, and self-regulation is a vital trait for enabling people to bring their behavior into line with those rules. The present investigation elaborated this view of self-regulation by testing the hypothesis that low or depleted self-control would increase violations of social norms and rules that involve a conflict between personal desires or habitual tendencies and situational requirements. Given the generality of the hypothesis, we sought to test it in a rather widely assorted set of spheres, using different forms of low self-control (state and trait), different social rules, and different means of measurement.

The link between low self-control and high tendency to violate social rules was found consistently across these studies despite the different procedures. In Study 1 and two pilot studies, a higher willingness to take ethical risks was associated with low trait self-control, manipulated depletion of self-control, and self-reported states of low (depleted) self-control. In Study 2, usage of socially disapproved (curse) words was linked to low trait self-control and was increased by a manipulated state of self-control depletion. Study 3 showed that self-control depletion increased the likelihood that people would violate one of the most basic and universal social norms, namely reciprocity (here in the sense of doing or not doing a favor for someone in return for receiving or not receiving a favor, respectively). In Study 4, an induced state of self-control depletion rendered people more likely to violate specific instructions from the situational authority figure (the experimenter) to remain silent. Study 5 linked low trait self-control to lower compliance with experimenter instructions regarding speech exercises over a two-week period. Last, Study 6 showed that low self-control on a laboratory, behavioral measure (the Stroop task) significantly predicted poorer compliance with instructions to alter one's method of performing various simple motor tasks (i.e., switching to use the other hand) in one's everyday life for two weeks.

Confidence in the generality of the conclusion, that low self-control predicts and promotes various violations of social rules, is strengthened by the convergence across these different methods. We found rule violations to be higher among people who scored low on a questionnaire measure of trait self-control, among people whose laboratory performance on a behavioral measure indicated poor trait self-control, among people whose state self-reports indicated feeling temporarily less capable of self-control, and among people whose current (state) capacity for self-control had been diminished by exercises designed to deplete their resources. Even more important, we found that low self-control contributed to quite different kinds of rule violations, including engaging in risky behavior that included serious violations of ethical rules, relatively minor flouting of norms for polite speech, disregarding one of the most basic and universal norms for reciprocating favors, and disobeying specific instructions from the situational authority figure (the experimenter). The increase in rule violations was found on objective behavioral measures, subjective rated willingness to perform hypothetical behaviors, and self-reported actual behavior, and they encompassed behavior limited to the specific laboratory session, as well as behavior performed at home over the course of a two-week longitudinal study. It included viola- tions of implicit, consensually understood, highly general rules about social behavior, widely recognized and explicitly illegal behaviors (e.g., forging signatures), and highly specific and explicitly stated behavioral instructions.

\section{Implications, Alternative Explanations, and Future Directions}

The convergence across different methods speaks against some alternative explanations that might be advanced for certain specific findings. For instance, it might be suggested that scoring low on the trait self-control scale bespeaks only a willingness to admit to misdeeds rather than actually lacking self-control (see Vohs, Baumeister, \& Ciarocco, 2004). That interpretation cannot however account for the findings based on manipulated low levels of self-control (depletion), nor for the directly observed (rather than self-reported) norm violations in Studies 2 and 3, nor with Study 6's finding that a behavioral index of trait self-control (Stroop performance) worked as well as the self-report trait scale for predicting failure to follow the experimenter's instructions.

The link between low self-control and ethical violation appeared to be direct, as far as we investigated other potentially contributing factors. That is, it was not related to gender, mood valence, emotional arousal, or perceived self-efficacy. And although some of our findings were correlational, others were based on experimental manipulations and therefore do permit causal interpretation.

One implication of the current work concerns the risk factors for violations of social rules and regulations. People who demonstrate a broad pattern of poor self-control (e.g., poor money management) can be considered at risk for violating norms and rules, and situations that place high self-regulatory demands on the individual are another risk factor. For example, after refraining from yelling at a co-worker, an employee should be especially likely to misreport his or her corporate expenses. Or, after paying effortful attention to a boring lecture, college students should be especially likely to push and shove as they exit the classroom, rather than exit politely and orderly. Social rules and regulations pertain to many aspects of life, and so low or depleted self-control can be considered risk factors for inappropriate or harmful behavior across a broad variety of contexts (e.g., perhaps especially in situations that require following explicit instructions that one does not want to follow, as in Studies 4-6).

Of course, we did not examine all types of social norms and regulations. Hence, it would be premature to conclude that low self-control contributes to all types of social norm and rule violations. Indeed, we posit that low self-control should cause people to violate norms that require the individual to override desires that conflict with socially appropriate standards. We would predict that low self-control does not impair following norms or rules that do not involve a conflict between internal and external desires, especially norms or rules that might be over learned or automatic.

One worthwhile avenue for future research would be to investigate whether low or depleted self-control reflects primarily an inability or rather an unwillingness to exert self-control. In the current studies, for instance, it seems reasonable that participants could have refrained from breaking social norms and rules (e.g., talking, using curse words) had they been sufficiently motivated. Still, the fact that increased motivation might 
compensate for low self-control does not necessarily mean that low self-control reflects a lack of motivation.

\section{Concluding Remarks}

Human social life is saturated with rules to an extent that is unthinkable in any other known species. In that sense, the successful functioning of human culture depends on people having a relatively powerful inner mechanism that helps them alter their behavior and override their impulses so as to conform to all manner of rules - tax laws, religious commandments, traffic regulations, etiquette, dress codes, moral pressures against discrimination and prejudicial speech, and the like. Moreover, it is essential that people follow rules even in the absence of societal enforcers able to threaten immediate punishment to rule breakers.

The present investigation was based on the assumption that self-regulation is the centrally important inner mechanism that enables people to alter their behavior so as to conform to rules. Consistent with that, we found that relative deficiencies in self-control were linked to or a direct cause of violations of assorted social rules.

To be sure, not all rule following is good. Psychologists have recognized for decades that obedience can produce hurtful behavior (e.g., Milgram, 1963), and human history has provided many examples of groups whose rules promoted destructive, violent, and costly actions by the members who followed those rules most closely (e.g., organized crime, intolerant religions, repressive governments, terrorist groups, professional torturers). On the whole, however, obeying norms and rules is highly desirable. Without obedience, it is hard to see how corporations, military units, or even families could function successfully. Economic marketplaces, scientific research, medical care, education, and other systems that enable societies to thrive depend on having rules. In fact, recent work has shown that the rule of law is positively associated with higher levels of societal happiness (Veenhoven, 2003).

Rules can however confer their benefits only if people obey them. Self-control isapparently vital for that, at least in some cases. A weakening of self-control among members of society may therefore contribute to a weakening of the social fabric generally.

\section{REFERENCES}

Baron, R. M., \& Kenny, D. A. (1986). The moderator-mediator variable distinction in social psychological research: Conceptual, strategic, and statistical considerations. Journal of Personality and Social Psychology, 51, 1173-1182. doi:10.1037/0022-3514.51.6.1173

Baumeister, R. F., Bratslavsky, E., Muraven, M., \& Tice, D. M. (1998). Self-control depletion: Is the active self a limited resource? Journal of Personality and Social Psychology, 74, 1252-1265. doi:10.1037/0022-3514.74.5.1252

Baumeister, R. F., Schmeichel, B. J., \& Vohs, K. D. (2007). Self-regulation. In E. T. Higgins, \& A. W. Kruglanski (Eds.), Social psychology: Handbook of basic principles (2nd ed., pp. 516-539). New York: Guilford.

Baumeister, R. F. (2005). The cultural animal: Human nature, meaning, and social life. New York: Oxford University Press.

Baumeister, R. F., \& Exline, J. J. (1999). Virtue, personality and social relations: Self-control as the moral muscle. Journal of Personality, 67, 1165-1194. doi:10.1111/1467-6494.00086

Cosmides, L., \& Tooby, J. (2004). Social exchange: The evolutionary design of a neurocognitive system. In M. S. Gazzaniga (Ed.), The cognitive neurosciences (pp. 1295-1308). Cambridge, MA: MIT.

Finkel, E. J., \& Campbell, W. K. (2001). Self-control and accommodation in close relationships: An interdependence analysis. Journal of Personality and Social Psychology, 81, 263-277. doi: 10.1037/0022-3514.81.2.263

Fisher, J. D., DePaulo, B. M. \& Nadler, A., (1981). Extending altruism beyond the altruistic act: The mixed effects of aid on the help recipent. In J. P. Rushton, \& R. M. Sorrentino (Eds.), Altruism and helping behavior: Social, personality, and developmental perspectives (pp. 367-502). Hillsdale, NJ: Erlbaum.

Gailliot, M. T., \& Baumeister, R. F. (2007). Self-regulation and sexual restraint: Dispositionally and temporarily poor self-regulatory abilities contribute to failures at restraining sexual behavior. Personality and Social Psychology Bulletin, 33, 173-186. doi: $10.1177 / 0146167206293472$

Gailliot, M. T., \& Baumeister, R. F. (2005). Self-control and business ethics: How strengthening the self benefits the corporation and the individual. In R. A. Giacalone, C. L. Jurkiewicz, \& C. Dunn (Eds.), Positive Psychology, Ethics, and Social Responsibility in Organizational Life. Greenwich, CT: Information Age.

Gailliot, M. T., Schmeichel, B. J., \& Baumeister, R. F. (2006). Selfregulatory processes defend against the threat of death: Effects of self-control depletion and trait self-control on thoughts and fears of dying. Journal of Personality and Social Psychology, 91, 49-62. doi:10.1037/0022-3514.91.1.49

Gilbert, D. T., Krull, D. S., \& Pelham, B. W. (1988). Of thoughts unspoken: Social inference and the self-regulation of behavior. Journal of Personality and Social Psychology, 55, 685-694. doi: $10.1037 / 0022-3514.55 .5 .685$

Gottfredson, M. R., \& Hirschi, T. (1990). A general theory of crime. Stanford, CA: Stanford University Press.

Gouldner, A. (1960). The norm of reciprocity: A preliminary statement. American Sociological Review, 25, 161-178. doi:10.2307/2092623

Greenberg, M. S. (1980). A theory of indebtedness. In K. Gergen, M. S. Greenberg, \& R. H. Willis (Eds.). Social exchange: Advances in theory and research (pp. 3-26). New York: Plenum. doi:10.1007/978-1-4613-3087-5_1

Kahan, D., Polivy, J., \& Herman, C. P. (2003). Conformity and dietary disinhibition: A test of the ego-strength model of self-regulation. International Journal of Eating Disorders, 32, 165-171. doi: $10.1002 /$ eat. 10132

MacLeod, C. M. (1991). Half a century of research on the Stroop effect: An integrative review. Psychological Bulletin, 109, 163-203. doi:10.1037/0033-2909.109.2.163

Mayer, J. D., \& Gaschke, Y. N. (1988). The experience and metaexperience of mood. Journal of Personality and Social Psychology, 55, 102-111. doi: $10.1037 / 0022-3514.55 .1 .102$

Milgram, S. (1963). Behavioral study of obedience. Journal of Abnormal and Social Psychology, 67, 371-378. doi:10.1037/h0040525

Mischel, W., Shoda, Y., \& Peake, P. K. (1988). The nature of adolescent competencies predicted by preschool delay of gratification. Journal of Personality and Social Psychology, 54, 687-696. doi:10.1037/0022-3514.54.4.687

Muraven, M., \& Baumeister, R. F. (2000). Self-regulation and depletion of limited resources: Does self-control resemble a muscle? Psychological Bulletin, 126, 247-259. doi:10.1037/0033-2909.126.2.247

Muraven, M., Collins, R. L., \& Neinhaus, K. (2002). Self-control and alcohol restraint: An initial application of the Self-Control Strength Model. Psychology of Addictive Behaviors, 16, 113-120. doi:10.1037/0893-164X.16.2.113

Oaten, M., Cheng, K., \& Baumeister, R. F., (2004). Strengthening the regulatory muscle: The longitudinal benefits of exercising self-controll (Manuscript in Preparation). Sydney: Macquarie University.

Pratt, T. C., \& Cullen, F. T. (2000). The empirical status of Gottfredson and Hirschi's general theory of crime: A meta-analysis. Criminology, 38, 931-964. doi:10.1111/j.1745-9125.2000.tb00911.x

Regan, R. T. (1971). Effects of a favor and liking on compliance. Journal of Experimental Social Psychology, 7, 627-639. doi:10.1016/0022-1031(71)90025-4

Richeson, J. A., \& Shelton, J. N. (2003). When prejudice does not pay: Effects of interracial contact on executive function. Psychological 


\section{T. GAILLIOT ET AL.}

Science, 14, 287-290. doi:10.1111/1467-9280.03437

Rubens, W. S. (1981). Sex and violence on TV. Journal of Advertising Research, 21, 13-20.

Schmeichel, B. J., Vohs, K. D., \& Baumeister, R. F. (2003). Intellectual performance and ego depletion: Role of the self in logical reasoning and other information processing. Journal of Personality and Social Psychology, 85, 33-46. doi:10.1037/0022-3514.85.1.33

Shiffrin, R. M., \& Schneider, W. (1977). Controlled and automatic human information processing: I. Detection, search, and attention. Psychological Review, 84, 1-66. doi:10.1037/0033-295X.84.1.1

Tangney, J. P., Baumeister, R. F., \& Boone, A. L. (2004). High selfcontrol predicts good adjustment, less pathology, better grades, and interpersonal success. Journal of Personality, 72, 271-322.

doi:10.1111/j.0022-3506.2004.00263.x

Twenge, J. M., Muraven, M., \& Tice, D. M. (2004). Measuring state self-control: Reliability, validity, and correlations with physical and psychological stress. San Diego, CA: San Diego State University.

Veenhoven, R. (2003) Happiness in nations. Presented at the Positive Psychology Summit Conference, Washington DC.

Vohs, K. D., Baumeister, R. F., \& Ciarocco, N. J. (2005). Self-regulation and self-presentation: Regulatory resource depletion impairs impression management and effortful self presentation depletes regulatory resources. Journal of Personality and Social Psychology, 88, 632-657. doi:10.1037/0022-3514.88.4.632

Weber, E. U., Blais, A., \& Betz, N. E. (2002). A domain-specific riskattitude scale: Measuring risk perceptions and risk behaviours. Journal of Behavioral Decision Making, 15, 263-290.

doi: $10.1002 / \mathrm{bdm} .414$ 